\title{
La Crítica de la razón pura de Kant como crítica inmanente
}

\author{
The criticism of Kant's pure reason as immanent criticism
}

Alessandro Caviglia ${ }^{1}$

\section{RESUMEN}

El presente trabajo presenta de qué manera la Crítica de la Razón Pura no solo incorpora una Metafísica crítica, sino también puede servir como base para desarrollar la teoría crítica de la sociedad, tal como lo hacen los representantes de la Escuela de Frankfurt. Esto es posible, si se ilumina el hecho de que la razón no es algo que se encuentra fuera del mundo, sino que se encuentra en las personas que se encuentran en un mundo social específico. De esta manera, la razón es la base que hace posible el intercambio de razones entre las personas, con el fin de desarrollar una crítica inmanente de la sociedad.

\section{Palabras clave}

Immanuel Kant, Crítica de la Razón Pura, Teoría Crítica de la Sociedad, Crítica inmanente, crítica externa de la sociedad.

\begin{abstract}
The current work expounds how the Critique of Pure Reason not only incorporates a critical Metaphysics, but can be useful as a basis for developing the critical theory of society, as the representatives of the Frankfurt School do. This is possible, illuminating the fact that reason is not something outside the world but is found in people who are in a specific social world. In this way, the reason is the basis that enables the exchange of reasons among people, in order to develop an immanent critique of society.
\end{abstract}

\section{Keywords}

Immanuel Kant, Critique of Pure Reason, Critical Theory of Society, Immanent Criticism, External Criticism of Society.

La conocida Escuela de Frankfurt desarrolló una teoría crítica de la sociedad cuya particularidad ha sido la crítica inmanente. Pero, también, desde sus inicios, con Horkheimer y Adorno, decidieron conectar sus investigaciones con las ideas de Hegel y Marx, y tomar distancia de Kant. La llamada Segunda Generación de la Teoría Crítica, bajo el liderazgo de Habermas acercó a la Escuela de Frankfurt a Kant, pero se apartó de la crítica inmanente. Con Honneth, y algunos de sus seguidores, se volvió a Hegel y se dejó de lado a Kant, para rehabilitar, entre otras cosas el concepto de crítica inmanente (aunque algunos de los estudiantes de Honneth, como Rainer Forst, se mantuvieron del lado de Kant). Parece ser que la relación Kant, crítica inmanente y teoría crítica es complicada, pero, sin embargo, es posible encontrar en la obra del filósofo de la Ilustración elementos que conduzcan al desarrollo de una crítica inmanente de la sociedad, especialmente en la Crítica de la razón pura. El presente texto tiene como objetivo realizar una exploración al respecto para poder lanzar unas primeras luces respecto a la posibilidad de una crítica inmanente desde obra de Kant.

En lo que sigue buscaré explorar las posibilidades una crítica inmanente de la sociedad partiendo desde la Crítica de la razón pura de Kant. Para ello 1) distinguiré la crítica inmanente de otras formas de crítica social, para 2) pasar a dar cuenta

Filósofo. Profesor del Departamento de Teología de la Pontificia Universidad Católica del Perú y de la Carrera Profesional de Filosofía de la Universidad Antonio Ruiz de Montoya 
de la crítica inmanente de la razón que Kant desarrolla en su obra, y 3) ver de qué manera esos principios críticos de los que el filósofo de Königsberg da cuenta pueden ser útiles para la crítica de la sociedad.

\section{1.- ¿Qué se entiende por crítica inmanente de la sociedad?}

La crítica inmanente de la sociedad que la Teoría Crítica va desarrollando se distingue de otras formas de crítica social. Para ganar claridad sobre el concepto de crítica inmanente, estableceremos la distinción entre esta y otras formas de crítica social. Para ello buscaremos establecer un marco lo suficientemente amplio para poder abarcar las diferentes formas de crítica social. Este marco distingue tres formas de crítica social: a) La crítica externa, b) la crítica interna y c) la crítica inmanente. Cada una de ellas se distingue por los diferentes principios de crítica que utilizan.

\section{1.- La crítica externa de la sociedad}

La crítica externa asume como punto de partida un principio externo a la misma sociedad que se está criticando. Dicho principio puede ser constructivo-universal o externo-particular. Por esta razón, es posible pensar en dos formas de crítica externa, aquella que se realiza desde un principio adquirido por construcción o aquella que se realiza de principios de una sociedad externa a la que se está criticando. Pero en ambos casos el punto de partida del que se desarrolla el principio de la crítica es trascendente. De, otra parte, el fundamento de la crítica se encuentra en la contradicción entre los parámetros externos y las prácticas propias de la sociedad. En el caso de la crítica externa constructivista el fundamento de la crítica se basa en un proceso de construcción y la validez o el alcance de la crítica es universal. Y, respecto del papel, se trata de una teoría normativa como juez ${ }^{2}$.
La crítica externa presenta dos formas básicas, ya sea que el punto de partida desde el que se articula el principio sea externo-particular o constructivo-universal. La primera es la crítica de una sociedad a otra, mientras que la segunda es la crítica que se realiza por medio de un proceso de abstracción del mundo social en su totalidad, por medio de la construcción de principios racionales o de otro tipo ${ }^{3}$.

La crítica externa de la sociedad desde otra sociedad recurre a principios críticos que provienen desde fuera de la sociedad en cuestión. Estos principios son elaborados desde fuera de la sociedad y pretenden ser criterios adecuados para criticar las relaciones sociales existentes en la actualidad. Un tipo de crítica externa es la que se realiza desde los principios normativos de una sociedad externa; por ejemplo, la crítica que se dirige a una sociedad porque no conoce la "religión Verdadera" (como en el caso de la crítica que realizaron los españoles a la sociedad prehispánica en América).

Otra estrategia de la crítica externa es la constructiva-universal. Puede desarrollarse por medio de la construcción de principios por medio de una toma de distancia de toda sociedad posible. Amparándose en los poderes de la razón, el crítico social puede elaborar principios críticos para toda sociedad posible, por eso es universal. Esta es la clase de crítica social que John Rawls realiza al presentar, por construcción, los principios de la justicia como imparcialidad, a partir de los cuales se puede criticar la sociedad en su Teoría de la justicia. Otro representante es Platón, quien construye, por medio de los poderes de una razón metafísica una Polis ideal en La república.

2 Jeaggi, Rahel; Kritik von Lebensformen, Berlin; Suhrkamp, 2014. p. 309.

3 Axel Honneth recuerda que es habitual en la Teoría Crítica distinguir entre la "crítica fuerte" y la "crítica débil". La crítica fuerte es la crítica externa a la sociedad (que Honneth asocia acertadamente con la posición que John Rawls asume en Teoría de la justicia - aunque no aclara si el Rawls del Liberalismo político, o de Justicia como imparcialidad. Una reformulación o El derecho de gentes también puede asociarse a esta crítica fuerte), mientras que la crítica débil es de carácter interna a la sociedad. Cf. Honneth, Axel; Crítica reconstructiva de la sociedad con salvedad genealógica. Sobre la idea de "crítica" en la Escuela de Frankfurt, en: Patologías de la razón. Historia y actualidad de la teoría crítica, Madrid: Katz, 2009. p. 54.

Ahora bien, lo que Honneth denomina "crítica fuerte" no se identifica con la primera forma de crítica que presentamos aquí, aquella de viene de una sociedad a otra, sino que sólo se identifica con la segunda forma. La razón puede ser porque la primera no parece ser filosóficamente tan relevante, pero nosotros consideramos que es políticamente relevante y que ha habido posiciones filosóficas que se han apegado a esta, comenzando por Aristóteles, quien consideraba superior la forma de vida de la polis griega frente a la de los pueblos bárbaros. 


\section{2.- La crítica interna de la sociedad} La crítica interna asume un punto de partida interno para elaborar el principio de la crítica. Dichos puntos de partida lo constituyen los valores, las normas y las convicciones compartidas por la sociedad, que son articulado a través de un principio de carácter hermenéutico. El fundamento de la crítica lo constituye la contradicción entre los ideales internos y la realidad. El carácter de la crítica es reconstructivo, mientras que su validez es interna a la sociedad y particular. Y la teoría no cumple ningún papel ${ }^{4}$. De esta manera, la crítica interna no procede por construcción, sino más bien por reconstrucción. Por medio de un ejercicio hermenéutico, el crítico social se remite a principios anclados en el pasado para reconstruir el orden normativo de la sociedad. Reformistas como Lutero señalaban que lo que estaban haciendo era restablecer el orden normativo desde los principios olvidados por la Iglesia Católica.

\section{3.-La crítica inmanente de la sociedad}

La crítica inmanente es interna y su punto de partida se haya en las normas subyacentes a las prácticas sociales. El fundamento de la crítica es la contradicción dialéctica al interior de la constelación de prácticas y normas sociales, es decir, el fundamento es lo que constituye la crisis. El carácter de la crítica inmanente es transformativo de la sociedad. Su validez radica en la racionalidad de las normas, en tanto justificación inmanente. Y el papel de la teoría es servir de instancia de análisis que revela la crisis y la contradicción ${ }^{5}$. De este modo, la crítica inmanente no procede ni por principios externos, ni por principios recogidos de la tradición ni del pasado. La crítica inmanente procede por principios operantes en la misma sociedad actual. De lo que se trata es de restituir la racionalidad de la práctica de la sociedad actual desde los mismos principios de la sociedad actual, tal como lo presenta Marx a Ruge en su conocida carta, que dice "[d]esarrollamos nuevos principios para el mundo sobre la base de los propios principios del mundo" 6 .
Lo inmanente de la crítica inmanente son los principios que se usan para realizarla. La crítica de las formas de vida es inmanente porque es a partir de los mismos principios que articulan la forma de vida que se realiza la crítica; es decir, la crítica tanto de la sociedad como de las formas de vidas y comunidades éticas se realiza cuando estas han perdido racionalidad. Pero la racionalidad es inmanente a las mismas sociedades, formas de vida o comunidades éticas. Desde fuera no es posible calificar a una sociedad, forma de vida o comunidad ética de racional o irracional, sino sólo desde dentro. Para que fuese de otro modo, debería haber parámetros externos de racionalidad que nos permita juzgar a las sociedades desde fuera, lo cual se resultaría ser una crítica externa en vez de inmanente. El conjunto de creencias, de vivencias y de principios que articulan una sociedad, una forma de vida o una comunidad ética están articulados de manera holista y la irracionalidad se constituye solo cuando las relaciones entre esos elementos generan contradicciones. Por ejemplo, cuando el conjunto de principios que regulan esa forma de vida entran en conflicto con las formas de producción y reproducción social y material de dichas formas de vida (esas contradicciones inherentes a las mismas formas de vida constituyen lo que Adorno denominada "vidas dañadas") ${ }^{7}$.

\section{2.- La Crítica de la razón pura y la crítica inmanente}

La Crítica de la razón pura de Kant presenta una crítica inmanente que se inscribe en la idea de la crítica inmanente de la sociedad tal como se presenta en la Teoría crítica. Pero no solo eso, sino que entender la crítica inmanente de la sociedad desde el texto de la Crítica permite percibir con mayor claridad la relación entre la experiencia de la crisis social, la crítica de la sociedad, y la manera en la que de ese proceso se pueden extraer principios prácticos de carácter inmanente que permiten realizar la crítica social. La Crítica que Kant presenta no procede desde fuera, partiendo de principios externos a la razón

\footnotetext{
4 Jeaggi, Rahel; Kritik von Lebensformen, Berlin; Suhrkamp, 2014. p. 309.

Jeaggi, Rahel; Kritik von Lebensformen, Berlin; Suhrkamp, 2014. p. 309.

Marx, Karl; Carta a Ruge de 1843. https://www.marxists.org/espanol/m-e/cartas/m09-43.htm

Cf. Adorno, Theodor; Minima moralia: reflexiones desde la vida dañada, Madrid: Akal, 2004.
} 
misma. La razón no es criticada desde principio metafísico trascendente alguno, como sí sucede en caso de la "Teoría del mundo de las ideas" desarrollada por Platón. Sino que la razón encuentra el principio de su crítica dentro de ella, detectando el punto en el que ella comienza a encontrarse en contradicción consigo misma. La razón encuentra que su disposición natural a la metafísica la conduce a sobrepasar sus propios límites a la hora de lanzarse al conocimiento, puestoquelaspreguntasquese planteadesbordan los límites de su capacidad de conocimiento, por ello coloca principios trascendentes que no tienen soporte alguno en la experiencia y de toda posibilidad de conocimiento. Pero, en este proceder, la razón cae en contradicciones consigo misma y se ve obligada a afirmar que el mundo tiene un comienzo, al tiempo que afirma que carece de comienzo; o que todo está sometido al determinismo basado en la causalidad natural y que, al mismo tiempo existe espontaneidad por libertad. En ese sentido que la razón se ve obligada a llevar a cabo una reflexión que permita salir de esos enredos en los que su disposición natural la coloca.

De esa manera, Kant afirma en la Crítica de la razón pura lo siguiente:

La razón tiene, en un género de sus conocimientos, el singular destino de verse agobiada por preguntas que no puede eludir, pues le son planteadas por la naturaleza de la razón misma, y que empero tampoco puede responder; pues sobrepasan toda facultad de la razón humana.

Y sigue diciendo:

Ella cae sin culpa suya en esta perplejidad. Comienza por principios cuyo uso es inevitable en el curso de la experiencia, y está a la vez suficientemente acreditada por ésta. Con ellos asciende (tal como su naturaleza lo requiere) cada vez más alto, hacia condiciones más remotas. Pero puesto que advierte que de esta manera su negocio debe quedar siempre inconcluso, porque las preguntas nunca se acaban, se ve por ello obligada a recurrir a principios que sobrepasan todo uso posible de la experiencia y que sin embargo parecen tan libres de sospecha, que incluso la común razón humana está de acuerdo con ellos. Pero así se precipita en oscuridades y en contradicciones (...).

Tal como lo afirma Kant, esta reflexión parte de la misma experiencia de la contradicción en la que se encuentra la razón, y a partir de dicha experiencia la razón realiza una crítica de sî misma desde los principios que están operando desde dentro. La crítica procede en superar la contradicción restituyendo la racionalidad. De esta manera, la razón restituye su coherencia interna partiendo del examen de la contradicción que se encuentra en ella y saliendo de ella con principios inmanentes a la misma razón. La crítica inmanente que realiza la razón de sî misma se desarrolla en tres campos principales, en el campo de la confrontación de los sistemas metafísicos, en los procesos históricos y en los procesos sociales. Para efectos del presente trabajo me concentraré en la forma en la que de los conflictos metafísicos se derivan principios prácticos para la sociedad.

\section{1.-La Crítica de la razón pura de Kant y los conflictos dogmáticos}

La Crítica de la razón pura de Immanuel Kant ha sido vista tradicionalmente como una obra de epistemología y de metafísica. Si la obra es leída con atención desde el inicio, parece que de eso se trata. De hecho, parece ser que la pregunta central de la obra es ¿cómo es posible la metafísica como ciencia? En la formulación de la pregunta está clara la doble orientación del texto tanto hacia la metafísica como hacia la epistemología. Esta forma de leer el libro de Kant parece reforzarse si se entiende que la parte central se encuentra en la sección dedicada a la "analítica trascendental", y que desde ese centro gira toda la discusión que se plantea. Desde esta perspectiva, los paralogismos y la dialéctica son secciones dependientes y no principales de la

8 Kant, Immanuel; Crítica de la razón pura, México: FCE, 2000. A VII - A VIII. (el subrayado es mío) p.5 
obra. De esta manera, a partir de esta lectura, la Crítica de la razón pura no permite extraer principios críticos ni para la política, ni para la moral, ni para la filosofía social, así como tampoco para la religión ni para el derecho.

Pero esta lectura termina por generar la idea de que las demás obras, en las que Kant presenta principios prácticos se encuentran desconectados de la Crítica de la razón pura. Esta lectura fue presentada por algunos neokantianos del cambio de siglo XIX y XX, y por Hans Kelsen, quien desdeñaba los aspectos sustantivos de las obras de Kant para quedarse solo con el formalismo de la analítica trascendental. Sin embargo, es posible ganar otra lectura del texto, desde la cual se extraigan principios prácticos. Una de esas lecturas es comprender la respuesta que da Kant a la pregunta ¿cómo es posible la metafísica como ciencia? como teniendo la siguiente respuesta: solo es posible ello si es que limitamos las pretensiones de conocimiento humano y renunciamos a tener conocimientos metafísicos trascendentes; es decir, señalando que sólo podemos conocer aquellos elementos que se dan en la experiencia y que la tarea de la filosofía deja de ser la de buscar conocimientos hiperfísicos para indagar cuáles son las condiciones de posibilidad del conocimiento empírico. Ello conduce directamente a la investigación trascendental y a la deducción de las categorías del entendimiento. Pero esta investigación de carácter lógico (propio de la analítica trascendental) tienen como finalidad ( $y$ trae como consecuencia) un elemento político. $\mathrm{Si}$ nadie puede abrogarse conocimientos de aspectos metafísicos trascendentes, entonces nadie puede decir que cuenta con el conocimiento de la naturaleza humana ni de la manera en la que las personas deben vivir sus vidas ni cuáles son las condiciones ni para la felicidad ni la realización o la calidad de vida de las personas, condiciones de las cuales algún iluminado se abrogue el derecho de señalar cuál es la forma de gobierno y que forma debe de tener la sociedad en vistas de tal supuesto conocimiento.

De esta manera, el texto de la primera crítica trae consigo una consecuencia importante: le cierra el paso a toda forma de dogmatismo, ya sea que éste se base en una iluminación sagrada o basada en una supuesta ciencia, ya sea que pretenda tener su origen en un conocimiento de la naturaleza humana o de las condiciones de realización o de calidad humana. De esta manera, se trata de un texto que tiene en su seno una profunda fuerza antidespótica. Justamente, el despotismo consiste en pretender gobernar a las personas de manera arbitraria alegando que se tiene un conocimiento del que realmente se carece. Con ello quedan fuera de juego las pretensiones despóticas de las Iglesias y de los absolutismos, así como de los proyectos desarrollistas (tan en boga en América Latina durante los años 60 y 70) o del proyecto político neoliberal de desarrollo del mercado o de la actual agenda política imperante en nuestros días, llamada "desarrollo humano". Todos estos proyectos suponen un conocimiento de objetos metafísicos que no se encuentra a nuestro alcance. Ello es la base de arbitrariedad de todos estos proyectos. Es decir, tales proyectos no se encuentran asistidos por razones y justificaciones en el sentido normativo estándar, es decir, que puedan ser aceptados razonablemente por cualquier persona en una situación determinada9.

Pero hay más, el despotismo, y la arbitrariedad que se encuentra a su base, es asistido por el dogmatismo. En los prólogos y en la introducción de la Crítica Kant presenta la manera en la que la metafísica, y con ella, toda la filosofía, ha caído en descrédito por haberse convertido en el campo de batalla de posiciones dogmáticas ${ }^{10}$. Las posiciones dogmáticas se caracterizan por encontrarse saturadas de razones consistentes, pero en las cuales la coherencia entre las razones en tan compacta que no permite el debate con otras posiciones y tampoco la contrastación con la experiencia. Dicha saturación conduce, inevitablemente a abrazar concepciones metafísicas trascendentes del mundo que permitan sujetar con firmeza las razones en torno a un núcleo duro. De esta manera, el dogmatismo conduce a afirmar la posesión de verdades de carácter teóricas de las que se posee un supuesto

9 Cf.Scanlon, Thomas; Lo que nos debemos unos a otros ¿Qué significa ser moral?, Barcelona: Paidós, 2003. En especial, los capítulos 4 y 5 .

9 Kant señala que "El campo de batalla de estas disputas se llama metafísica" KANT, Immanuel; Crítica de la razón pura, México: FCE, 2000. AVIII. 
conocimiento metafísico trascendente y que configuran el carácter compacto de las razones en cuestión. Ello hace que el encuentro con otros sistemas dogmáticos se presente como una lucha a muerte. Pero incluso las posiciones dogmáticas se enfrentan a posiciones depuradas por la crítica o frente a la experiencia que puede cuestionar sus pretensiones de validez. Este enfrentamiento entre posiciones dogmáticas no es algo que se encuentre sólo a nivel metafísico. Sino que se encuentra con claridad en los conflictos históricos ${ }^{11}$. Incluso el escepticismo frente a las posiciones dogmáticas se encuentra hecho del mismo material de sus rivales dogmáticos, puesto que ambos se instalan en posiciones teóricas dirigidas a debatir respecto del conocimiento o no conocimiento de determinados objetos. De esta manera, el escepticismo no se presenta como una solución para la tan dañada metafísica. Por esa razón, Kant había percibido con claridad que sólo la crítica puede sacar a la filosofía de este callejón sin salida.

\section{2.-La Crítica como respuesta a la crisis}

Hemos visto de qué manera la crítica inmanente se presenta como respuesta a la crisis generada en la sociedad, en la forma de vida o en la comunidad ética. La crisis se produce cuando la racionalidad es reemplazada por la contradicción. Los principios y las prácticas de la sociedad o de la forma de vida entran en contradicción entre sí, y la crítica tiene como objetivo restituir la racionalidad transformando a la misma sociedad. Esta restitución de racionalidad se realiza a través de principios críticos que brotan de la misma sociedad existente. Pero aquello que sucede en la sociedad también puede darse en el seno mismo de la metafísica.

Ahora bien, los conflictos entre posiciones dogmáticas en metafísica no se dan en un "mundo paralelo" sino que tienen directamente efectos prácticos en el mundo social, en las formas de vidas y en las comunidades éticas. Los principios dogmáticos guían las acciones de las personas a conflictos sociales irreconciliables o a vidas dañadas ${ }^{12}$. En este sentido, la crítica de las posiciones dogmáticas en metafísica es crítica social.

La crítica es la respuesta que encuentra Kant a la crisis de la metafísica. Y la respuesta que da la crítica es extrayendo del conflicto entre las posiciones dogmáticas principios prácticos. Ello sucede en las antinomias, especialmente en la tercera, aquella que enfrenta el determinismo con la libertad. De esta manera, se abre dos ámbitos de la razón: el ámbito teórico y el ámbito práctico. Mientras que el ámbito teórico se encuentra dirigido a dar explicaciones causales del mundo de la experiencia, el ámbito práctico se encuentra dirigido a producir principios prácticos. Así que mientras que la razón teórica otorga explicaciones, la razón práctica ofrece razones. Además, mientras que las explicaciones tienen un contenido, las razones tienen no sólo un contenido, sino además un carácter, es decir, son morales o no lo son. Las razones se distinguen de las explicaciones en que son prácticas y se encuentran orientadas a la acción. Las explicaciones, en cambio, son puramente teóricas. En esto queda claro que de las explicaciones teóricas no se pueden extraer principios para la acción, ya que los principios para la acción se sustentan en razones (son sustentados y cuestionados por medio de razones) y no en explicaciones.

La resolución de los conflictos teóricos a través del proceso de extraer de ellos principios prácticos arroja resultados directos en la vida social, restituyendo la racionalidad perdida. Esta restitución no se realiza trayendo principios externos, sino que del análisis del conflicto de los principios dogmáticos que están operando en la misma sociedad se extraen principios prácticos. Estos principios prácticos tienen la posibilidad de restituir la racionalidad puesto que ofrecen

11 Ejemplo de esto lo constituye Las guerras del Peloponeso. Cf. Alegría, Ciro; La crisis como antinomia histórica: sobre la revelación de la verdad, en: Giusti, Miguel, Raúl Gutierrez y Elizabeth Salmón (eds.), La verdad nos hace libres. Sobre las relaciones entre filosofía, derechos humanos, religión y universalidad, Lima: PUCP, 2015.

12 El conflicto armado interno en el Perú enfrento a sectores de la población que actuaban guiados por ideas y principios metafísicos de carácter dogmáticos. A causa del dogmatismo de los principios en acción, la crudeza del conflicto se radicalizó En los años posteriores al conflicto asistimos a la tragedia de personas cuyas vidas han sido seriamente dañadas, ya sea por que mantienen ideas dogmáticas en sus cabezas o porque han sido agredidos por quienes, en nombre de principios metafísicos, han ejercido dominación en sus vidas, reduciendo los espacios de sus vidas como personas autónomas. 
razones para la acción. En cambio, el conflicto se mantiene irresuelto y la racionalidad permanece quebrada si las personas se mantienen en sus posiciones dogmáticas anteriores. Dichas posiciones dogmáticas dotan a las personas de supuestos conocimientos revelados o científicos sobre el mundo y las vidas de los sujetos. Las personas, así atrapadas en el ensueño de sus posiciones dogmáticas no tienen la posibilidad de entender que no pueden tener esos supuestos conocimientos. No les es posible entender que lo único que se puede conocer es lo dado en las experiencias y que las ideas que provienen de la razón tienen solo un sentido práctico, pero no teórico.

Dicho conflicto teórico se mantiene vibrante en las posiciones políticas imperantes en las sociedades contemporáneas: de una parte nos encontramos ante los defensores de la democracia constitucional, inspirados en formas renovadas de positivismo (como lo es el llamado neoconstitucionalismo); del otro lado encontramos la concepción, igualmente dogmática, de la democracia plebiscitaria y populista. El conflicto entre ambas posiciones dogmáticas está terminando por desgarrar a las sociedades democráticas y sumiéndolas en una profunda crisis. Esta antinomia social no es otra que la del neoliberalismo y el neopopulismo

En cambio, cuando se entiende que esas ideas que la razón tiene no aportan conocimientos constitutivos, sino solo principios prácticos, se restituye la racionalidad y se abandona la situación de crisis tanto metafísica como social. El abandono de la crisis es posible gracias a la crítica de la razón, es decir, a la denuncia de las posiciones metafísicas y la extracción de principios prácticos. Esta crítica es inmanente porque todo esto se realiza en la experiencia de las personas en la sociedad actualmente existente. La crítica arroja un principio práctico que es el de la no instrumentalización de las personas.

\section{3.- El principio de no instrumentalización}

Un principio práctico central es el de la no instrumentalización. Esta exigencia de no instrumentalización brota como principio práctico del conflicto dialéctico entre posiciones dogmáticas, tal como aparecen en las antinomias de la razón pura, tal como Kant lo presenta en la Crítica de la razón pura. Especialmente, en la antinomia entre determinismo y libertad. De un lado se afirma que todo se encuentra determinado por causas, de modo que no existen causas incausadas, es decir, no existe la libertad; de otra parte, se afirma que existe causalidad por libertad ${ }^{13}$. Pero ambas posiciones se presentan como posiciones antinómicas asumidas como conocimientos, cuando se trata de ideas de la razón que no deben ser tomadas como conocimientos sino como ideas críticas. De allí brota la exigencia de no instrumentalización de ninguna persona.

Este principio se presenta con claridad en la segunda formulación del imperativo categórico, que Kant presenta en la Fundamentación de la metafísica de las costumbres: "Obra de tal modo que uses a la humanidad, tanto en tu propia persona como en la persona de cualquier otro, siempre al mismo tiempo como fin y nunca simplemente como medio" ${ }^{14}$.

Esta exigencia de no instrumentalización tiene tres aspectos que es necesario subrayar:

a) En primer lugar, que no podemos utilizar a las personas como medios para nuestros propios fines. Es decir, no podemos instrumentalizarlas $y$ tratarlas como objetos o cosas. Existe una diferencia entre las personas y las cosas. Las cosas pueden ser utilizadas como medios e instrumentos para nuestros fines, en cambio, las personas no pueden ser tratadas

13 La tercera antinomia señala en la tesis que "la causalidad según leyes de la naturaleza no es la única de la que puedan ser derivados todos los fenómenos del mundo. Es necesario, para explicarlos, admitir además una causalidad por libertad", mientras que la antítesis indica que "no hay libertad, sino que todo en el mundo acontece solamente según leyes de la naturaleza". Kant, Immanuel; Crítica de la razón pura, México: FCE, 2000. A444 (B472).

14 Kant, Immanuel; Fundamentación para una metafísica de las costumbres, Madrid: Alianza Editorial, 2002. P. 116. 
de esta manera debido a que ellas cuentan con personalidad moral. Pero además hay que tener presente que la segunda formulación del imperativo categórico está señalando que la persona debe ser tratada "siempre al mismo tiempo". Esto quiere decir que debe ser considerada como un fin y como un medio al mismo tiempo. Esta tensión que se expresa en la idea práctica de no instrumentalización permanecerá sin resolverse, puesto que la persona, dentro de los sistemas sociales son pesadas como medios a la vez que como fines en sí mismos. Así, el derecho y la economía consideran a las personas como medios, en el sentido de que ambos sistemas ejercen interferencias en las conductas de las personas, de la misma manera en la que los demás sistemas sociales lo hacen. Pero esta interferencia adquiere su validez sólo si no es arbitraria, sino que se realiza a través de reglas conocidas y producidas por los involucrados, considerados como colegisladores. En el caso que campee la arbitrariedad, se instala en las relaciones sociales un a relación entre personas basadas en la dominación.

b) En segundo lugar, que debemos de considerarlas con el derecho de darle fines a sus propias vidas y que no podemos proyectarles desde fuera proyectos de vida o fines de su existencia. De esta manera, nadie tiene derecho a indicarnos cuál es el tipo de vida que debemos realizar, ni qué religión debemos abrazar. Tampoco puede imponerle un proyecto un proyecto de desarrollo, como el proyecto de desarrollo económico o humano ${ }^{15}$. c) Y,entercerlugar, debemos de considerar a las personas como teniendo un derecho básico a exigir justificaciones de las normas del orden social en el que se encuentran insertos ${ }^{16}$.

De esta manera, en la formulación presentada, lo que encontramos es la fuerza republicana de Kant centrada en la idea del ser humano como autónomo. La autonomía de las personas resulta ser el corazón del republicanismo de Kant, reactualizado con lucha fuerfa por Habermas y Petit.

La exigencia de no instrumentalización de persona alguna no se extrae de ningún conocimiento que tengamos sobre los seres humanos ni de su naturaleza. Quizás la ciencia médica pueda tener conocimientos valiosos respecto del funcionamiento de determinados órganos del cuerpo humano, pero eso no significa que conozcan algo así como la naturaleza humana. Igualmente, los sacerdotes pueden tener bellas representaciones del alma humana, pero dichas representaciones no se asientan en conocimiento alguno, sino en lo que aparece en los textos sagrados. De manera que lo único que podemos afirmar es que no tenemos conocimiento ni acceso místico a la naturaleza o la esencia humana.

Dicha imposibilidad de conocimiento es presentada con claridad a partir de la crítica de la razón. Y es en virtud de esa imposibilidad que nos encontramos en condiciones de afirmar que ninguna persona debe ser instrumentalizada. Esta exigencia de no instrumentalización es el resultado de la operación crítica para enfrentar la crisis de la razón expresada en la tercera antinomia. Como se trata de una operación realizada por la razón, podemos afirmar que debemos considerar a la persona como si fuese un "centro de razones"17, es decir, tenemos la obligación de considerar a la persona como alguien que puede dar y

15 Desde la exigencia que brota de la segunda formulación del imperativo categórico se levanta una crítica a modelo de desarrollo económico que brota del neoliberalismo, como también a los modelos sociales que se han impuesto desde los 50 en América Latina, bajo el nombre de desarrollismo. Lo mismo sucede con el concepto de desarrollo humano desarrollado por Amartya Sen y Martha Nussbaum. Todos estos enfoques respecto del desarrollo suponen una concepción de naturaleza humana y un conocimiento metafísico de la misma, cosa de la que carecemos.

16 Este tercer aspecto ha sido desarrollado por Rainer Forst. Cf. FORST, Rainer; The Right to Justification, New York Columbia U. P., 2012. pp. 20-22.

17 Cf. Scalon, Thomas; Lo que nos debemos unos a otros ¿Qué significa ser moral?, Barcelona: Paidós, 2003. 
recibir razones. Thomas Scanlon, al interpretar la "razón" como la posibilidad de las razones lo que hace es liberar una fuerza contenida en la idea de Razón que Kant había asentado. De esta manera se produce un desarrollo doble. De una parte, la "dignidad de la Razón" se transmite a la dignidad de las personas. De otra parte, la exigencia de no instrumentalización se traduce en la exigencia de considerar a las personas como un centro de razones, con la capacidad de dar y recibir razones, es decir, la exigencia de ofrecer justificaciones respecto de las normas.

Considerar al ser humano como un centro de razones no significa tener conocimiento alguno respecto de la naturaleza humana. La Razón o las razones no son objetos metafísicos trascendentes. No se trata de conocimientos teóricos, sino de ideas de la razón práctica. El intercambio de razones supone la justificación mutua $y$ recíprocas ${ }^{18}$. El intercambio recíproco y mutuo de razones termina restituyendo la racionalidad de las relaciones dentro de la sociedad, así como dentro de las formas de vida y de las comunidades éticas. Esto coloca a las personas como autónomas y no sometidas a dominación. La consideración de las personas como centros de razones y justificaciones los prefigura como seres autónomos. La autonomía supone el hecho de que las personas son colegisladoras de las normas morales en un intercambio fluido de razones, al tiempo que apunta a la idea de qua a ninguna persona se le puede imponer una norma o una relación a la que ella no pueda dar su libre consentimiento. De este modo, el principio de no instrumentalización, incorporando la idea de la persona como centro de razones junto con la idea de autonomía, se presenta como un principio poderosamente de crítica inmanente que es importante tomar en cuenta en el debate.

18 DFORST, Rainer; The Right to Justification, New York: Columbia U. P., 2012. 


\section{REFERENCIAS}

Adorno, Theodor (2004) Minima moralia: reflexiones desde la vida dañada, Madrid: Akal.

Alegría, Ciro (2015) La crisis como antinomia histórica: sobre la revelación de la verdad, en: Giusti, Miguel, Raúl Gutiérrez y Elizabeth Salmón (eds.), La verdad nos hace libres. Sobre las relaciones entre filosofía, derechos humanos, religión y universalidad, Lima: PUCP.

Forst, Rainer (2012) The Right to Justification, New York: Columbia U. P.

Honneth, Axel (2009) Crítica reconstructiva de la sociedad con salvedad genealógica. Sobre la idea de "crítica" en la Escuela de Frankfurt, en: Patologías de la razón. Historia y actualidad de la teoría crítica, Madrid: Katz.

Jeaggi, Rahel (2014) Kritik von Lebensformen, Berlin; Suhrkamp.

Kant Immanuel (2000) Crítica de la razón pura, México: FCE.

Kant, Immanuel (2002) Fundamentación para una metafísica de las costumbres, Madrid: Alianza Editorial.

Marx, Karl; Carta a Ruge de 1843. https://www.marxists.org/espanol/m-e/cartas/m09-43.htm

Scalo, Thomas (2003) Lo que nos debemos unos a otros ¿Qué significa ser moral?, Barcelona: Paidós.

Fecha de recepción: 17-05-17

Fecha de aceptación: 03-10-17 